\title{
O Ensino da Saúde Coletiva no Método de Aprendizagem Baseado em Problemas: uma Experiência da Faculdade de Medicina de Marilia
}

PALAVRAS-CHAVE:

- Educação Médica;

- Saúde Pública;

- Sociologia Médica;

- Aprendizagem Baseada em Problemas.

KEY-WORDS:

- Education, Medical;

- Public Health;

- Sociology, Medical;

- Problem-Based Learning.

Recebido em: 27/04/2005

Reencaminhado em:24/03/2006

Aprovado em: 04/09/2006

\section{Teaching Collective Health using Problem Based Learning: an Experience at the Faculty of Medicina of Marilia}

Nelson Felice de Barros ${ }^{1}$ Lídia C. de Almeida Lourenço ${ }^{2}$

\begin{abstract}
RESUMO
Este trabalho relata a estratégia de incorporação das bases da Saúde Coletiva no currículo da Faculdade de Medicina de Marília (Famema). Em 1991, a Famema passou a desenvolver o Projeto UNI, financiado pela Fundação Kellogg, iniciando um conjunto de mudanças no ensino de Medicina, resultando, em 1997, na introdução do método de ensino da Aprendizagem Baseada em Problemas (ABP). A ABP trabalha com a perspectiva holística do processo ensinoaprendizagem e, por isso, estimula a participação ativa dos estudantes, principalmente, na cooperação em pequenos grupos; no auto-estudo e na educação multidisciplinar. Algum tempo após a introdução do ABP, identificou-se a dificuldade do uso de explicações das dimensões psicológicas e sociais para os problemas. A solução construída para a incorporação da dimensão social nos problemas foi a adoção da perspectiva sociológica das categorias fundantes da Saúde Coletiva: tempo, espaço e pessoa. O resultado foi a construção de uma matriz formada por seis tópicos e orientada para estimular os alunos a alcançar as noções de totalidade e integralidade do cuidado em saúde.
\end{abstract}

\begin{abstract}
This paper relates the strategy of introducing the bases of Collective Health to the curriculum of the Faculty of Medicine of Marilia (Famema). In 1991, Famema started the UNI Project funded by the Kellogg Foundation, with this initiating a set of changes in medical teaching that in 1997 resulted in the introduction of Problem Based Learning. Problem Based Learning works with a holistic view of the teaching-learning process, encouraging students to actively participate, mainly through small group co-operations, self-study and multidisciplinary education. Some time after the introduction of PBL, difficulties were identified with respect to working with psychological e sociological issues. The solution found for incorporating the social dimension of problems was adopting the sociological perspective of the basic conceits of Collective Health: time, space and the individual. The result was the construction of an analytical matrix composed by six topics, aimed at stimulating the students to achieve the dimensions of totality and integrality of collective health care.
\end{abstract}




\section{INTRODUÇÃO}

Nos últimos anos, tem se produzido intenso debate em torno da reforma curricular das escolas médicas no Brasil1-8. Um dos maiores desafios para o sucesso dessas mudanças é a adoção de uma metodologia mais holística e de métodos mais participativos.

Acredita-se que uma forma de alcançar essas mudanças no campo da saúde é a aproximação entre a universidade e os serviços. Obviamente, não é possível uma única estratégia de aproximação para todo o Brasil, mas a maior parte procura introduzir alunos nas unidades da rede para conhecerem a realidade "de um modo estranho ao da universidade, promovendo mobilização do corpo, do afeto e do pensamento, e gerando novo padrão de exigência de aprendiza$\mathrm{do}^{\prime \prime \prime}$.

O ensino médico com a perspectiva coletiva é bastante antigo nas ciências da saúde ${ }^{10}$, mas, com o processo de reforma curricular, sofreu diferentes transformações. Uma das escolas médicas que adotou mudanças foi a Faculdade de Medicina de Marília (Famema). A partir de 1991, começou a participar do Projeto UNI, financiado pela Fundação Kellogg, que preconizava o estreitamento das relações com a comunidade e com os serviços de saúde. Algumas mudanças estruturais foram necessárias, e foi escolhida a metodologia da Aprendizagem Baseada em Problemas (ABP), de acordo com os preceitos da Universidade de MacMaster (Canadá) e de Maastrich (Holanda).
Neste artigo, apresentamos uma proposta de incorporação de elementos da Saúde Coletiva aos problemas da ABP na Famema.

\section{O MÉTODO DE APRENDIZAGEM BASEADA EM PROBLEMAS}

Por volta de 1965, foi desenvolvido o método da Aprendizagem Baseada em Problemas ${ }^{11-14}$, na Faculdade de Ciências da Saúde da Universidade de McMaster, no Canadá, sob a influência da metodologia do estudo de casos empregada nos anos 1920, na Escola de Direito de Harvard.

No contexto da escola médica, a ABP foi e ainda é uma ação de contracultura na medida em que é um método de aprendizagem ativa, que procura compreender os princípios e os processos dos fenômenos investigados e que estimula o interesse pela investigação.

A ABP pressupõe: cooperar em pequenos grupos; condução do tutor; auto-estudo; educação multidisciplinar; educação em bloco e teste progressivo.

\section{O PROBLEMA: FUNDAMENTO DO MÉTODO}

O problema é a parte mais interna da ABP e deverá plantar no aluno a dúvida, estimulando a formulação de questões. Trata-se do instrumento de promoção da primeira ruptura epistemológica $15,16,17,18$ ou seja, da passagem das explicações fundadas no senso comum para as baseadas no conhecimento científico. Portanto, é a ferramenta que propiciará a construção-passagem do problema social para o problema sociológico.

\section{Problema social $\rightarrow$ Problema sociológico}

\footnotetext{
"Uma situação que afeta um número significativo de pessoas e que é tida por elas como uma causa de dificuldade ou de infelicidade, capaz de ser corrigida. Assim, consiste tanto numa situação objetiva quanto numa interpretação social subjetiva"19.
}

"Problema sociológico ou problema científico são problemas do conhecimento: existem quando a relação entre dois ou mais acontecimentos ou séries de acontecimentos é desconhecida"19.
Assim, a partir da apresentação de algumas referências e sinais de um indivíduo ou coletivo, o estudante formula questões para compreender a determinação multicausal do desequilíbrio, bem como a sistematização dos sinais em sintomas. Segundo Caprara ${ }^{14}$, o problema:

Funciona como 'ativador' dos conhecimentos prévios; constitui o foco para aprendizagem de conhecimentos oriundos de diversas fontes; fornece o contexto para a aprendizagem; constitui o elemento gerador da motivação intrínseca dos estudantes ${ }^{14}$.

Entre outras questões sobre os problemas, existe uma de cunho epistemológico. Sabidamente, o modelo biomédico é criticado pelo reducionismo, por privilegiar o aspecto biológico do processo saúde-doença em detrimento do psicológico e do social. Dessa maneira, uma tarefa extra para os problemas na ABP é alcançar a integralidade, estimulando as relações sociopsicomédicas ou psicossociomédicas, em lugar da exclusividade médico-psicossocial.

Pode parecer apenas um jogo de palavras, mas não é, pois o processo de construção de problemas na Famema foi amadurecendo. Inicialmente, refletia a justaposição de conteúdos, ao incluir situações que respondiam mais à demanda de "criar um gancho" do que propriamente reproduzir e/ou criar contextos e cenários relevantes de reflexão para estimu- 
lar a aprendizagem do aluno. Os estudantes tiveram um papel fundamental em denunciar "os penduricalhos" de cada problema, em particular aqueles que supostamente deveriam ensejar uma discussão dos conteúdos "não biológicos"20.

Os problemas podem ser de tipo descritivo, explicativo, de obstáculo de processo e de dilema; e devem conter título sugestivo e que direcione o interesse; texto claro, não muito extenso, nem muito prolixo; e instruções ou interrogações que dirijam a discussão para um tema definido e que explicitem como abordar o problema ${ }^{14}$.

\section{INCLUSÃO DE ELEMENTOS DA SAÚDE COLETIVA NOS PROBLEMAS DA ABP}

O objetivo da proposta foi introduzir elementos da organização social nos problemas da $\mathrm{ABP}$, compreendendo que eles devem conter estrutura e processo, alcançando a totalidade como produto e a totalização como método ${ }^{21}$. Assim, por um lado, insere-se nos problemas um sentido de (re)estruturação do conjunto de dimensões qualitativas e quantitativas da economia, da política, da cultura, da epidemiologia, etc; e, por outro lado, introduz-se a dúvida sociológica de identificar se, após as mudanças, se trata de outra sociedade ou da mesma sociedade em movimento.

O meio de introduzir esses elementos foi trabalhar com as categorias constitutivas, simultaneamente, da organização social e da Saúde Coletiva: o tempo, o espaço, a pessoa e os modelos explicativos do processo saúde-doença. Embora essas categorias estejam presentes na malha conceitual apresentada por Venturelli22, a forma como as introduzimos em nossa proposta é diferente.

A forma de operacionalizá-las foi tomar o conjunto de problemas da 1a série como uma totalidade, na qual são identificadas diferentes categorias da organização social. Assim, cada problema teve um aspecto do tempo, do espaço, da pessoa e dos modelos explicativos do processo saúde-doença, levando em consideração também a relevância, a seqüência lógica, a extensão, a factibilidade, a contextualização, a monitoração e a avaliação ${ }^{14}$.

\section{Tempo}

A noção de tempo é fundante da racionalidade ocidental, mas não é única em seu entendimento estrutural e simbólico. Estruturalmente, pode ser diferenciada em formas puras de passado, presente e futuro ou em híbridos sucessivos de passado-presente e presente-futuro. Simbolicamente, o tempo pode ser compreendido como o resultante da elaboração e interação de elementos coletivos de cada cultura.

Decorre da categoria tempo a demarcação dos intervalos da vida social e a operacionalização com os pares tempo line- ar/tempo cíclico e tempo histórico/tempo mítico. O "desencanto do mundo" foi sentenciado ao identificar a opção da racionalidade ocidental pelo racionalismo, portanto pelos tempos linear e histórico, em detrimento das racionalidades "tradicionais", de traço holístico, apoiadas nos tempos cíclico e mítico.

No quadro dos tempos, encontram-se as formas estruturais puras: passado (remoto/recente), presente e futuro (próximo/longínquo) ${ }^{23}$. Todavia, pode-se construir, ainda, o quadro da experiência do tempo híbrido: passado-presente, que delimita duração, memória de longo prazo, simultaneidade e sucessão; e presente-futuro, que define o tempo de curto prazo ou a percepção de intervalos curtos, ritmo ou timing, além da perspectiva temporal com a experiência do vir-a-ser.

Assim, é possível criar um problema que esteja se desenvolvendo no instante, na atualidade, na década passada, nos anos 1970, numa série histórica, etc., proporcionando o resgate temporal, a construção de cenários e contextos, e a determinação cronológica dos problemas de saúde.

\section{Espaço}

O espaço é outra noção fundante da racionalidade ocidental e, como o tempo, também tem representação diferenciada, estrutural e simbolicamente. Uma ciência da demarcação dos espaços estruturais é a geografia física, com o estudo das formações rochosas, relevos, climas, etc. Por sua vez, o espaço simbólico pode ser estudado pela ciência política e geografia, na justaposição que formou a geopolítica como disciplina. Certamente, a máxima especialização simbólica da geopolítica traduz-se no exercício da cartografia, que reduz e amplia as proporções do foco.

"O espaço é formado por um conjunto indissociável, solidário e também contraditório, de sistemas de objetos e sistemas de ações, não considerados isoladamente, mas como um quadro único no qual a história se dá"24. Continua Santos:

No começo era a natureza selvagem, formada por objetos naturais, que ao longo da história vão sendo substituídos por objetos fabricados, objetos técnicos, mecanizados e, depois, cibernéticos, fazendo com que a natureza artificial tenda a funcionar como uma máquina. Através da presença desses objetos técnicos o espaço é marcado por esses acréscimos ${ }^{24}$.

Ao adotarmos esse conceito de espaço, estamos ampliando a perspectiva do espaço naturalizado do positivismo, para identificá-lo como resultante da atividade histórica e dialética dos homens.

No caso da saúde, o espaço passa a ser um território cujos objetos técnicos presentes são as redes de relações criadas pelos coeficientes de morbi-mortalidade do local, pelas dife- 
rentes alternativas de cuidado, pela complexidade dos serviços instalados, pelo modelo gerencial e pelas políticas públicas da saúde local e nacional.

Assim, para qualificar o espaço, que pode ser do tamanho de um bairro, região, cidade, município, etc., deve-se identificar muito além do nome, latitude e altitude, ou seja, é necessário destacar a organização das suas práticas e o modelo de gerenciamento e atenção dos serviços.

\section{Pessoa: o hábito individual e o habitus coletivo}

O conceito de habitus foi mais recentemente desenvolvido por Bourdieu. Trata-se de constructo teórico complexo, porém com boas condições de operacionalização. O habitus apresenta-se como um estado:

Quase biológico, do [corpo social] se reproduzir. (...) Um segundo sistema de hereditariedade propriamente social que tende a assegurar, mediante a transmissão consciente ou inconsciente do capital acumulado, a perpetuação das estruturas sociais ou das relações de ordem que formam a 'ordem social' (...) através de mudança incessante e da renovação permanente, dos indivíduos, claro, mas também das manifestações da diferença, o que faz falar constantemente em 'mutação' 25 .

As demarcações "quase biológico", "hereditário" e "mutação" são bastante importantes, pois com elas explicita-se a força reprodutora da estrutura social e da cultura, mas também garante-se que não serão tomadas como determinantes exclusivos.

Em outro trecho, Bourdieu ${ }^{25}$ afirma ser o habitus

Um sistema de disposições duráveis e transferíveis que integram todas as experiências passadas e funciona a todo momento como matriz de preocupações, apreciações e ações. O habitus torna possível o cumprimento de tarefas infinitamente diferenciais, graças às transferências analógicas e esquemas que permitem resolver os problemas, da mesma forma, graças às correções incessantes dos resultados obtidos e dialeticamente produzidos por estes resultados ${ }^{25}$.

Assim, para apresentar as pessoas em sua condição social, pode-se partir da definição de habitus para qualificar seus atributos e os do grupo a que ele pertence. Considerando que as pessoas são sujeitos dos problemas, é importante qualificar sua posição social, na estrutura social, e sua condição social, no plano da cultura.

A estrutura social ressalta a diferença, ou seja, o modo como as pessoas se relacionam de acordo com suas posições sociais. A teoria dos papéis sociais é bastante adequada para esse tipo de análise, dado que, além de identificar o indivíduo na posição, também qualifica seus atributos de poder, prestígio e perspectiva ${ }^{26}$.

\section{Atributos de identificação na estrutura social}

\begin{tabular}{l|l}
\hline \multicolumn{1}{c|}{ Atributo } & \multicolumn{1}{c}{ Definição } \\
\hline Papel social & cada posição social apresenta um conjunto de expectativas, aquilo que se espera que se faça naquela posição \\
\hline Poder & capacidade de um ator para fazer valer seu poder em relação aos outros na organização social \\
\hline Prestígio & honra que as pessoas atribuem a uma posição na estrutura social \\
\hline Perspectiva & ângulo e lentes através dos quais se enxergam o mundo e as possibilidades nele \\
\hline
\end{tabular}

Por outro lado, como complemento da inserção na estrutura social, apresenta-se a condição social, qualificada por sua identidade cultural. O estudo da identidade é bastante complexo, sendo possível defini-la pela participação do grupo dos proprietários ou dos não proprietári- os, como pensou Marx de maneira geral, e defini-la de acordo com a posição e condição social, como desenvolveu $^{25}$.

Alguns atributos que qualificam a condição social dos indivíduos são as crenças, os valores e as normas. 
Atributos de identificação cultural

\begin{tabular}{|c|c|}
\hline Atributo & Definição \\
\hline Crenças & $\begin{array}{l}\text { - grupos desenvolvem filosofia, sistema de crenças, visão da realidade que lhes é útil e que funciona para a } \\
\text { organização das pessoas; } \\
\text { - as idéias que funcionam se tornam verdades; uma vez que cada organização social se encontra numa } \\
\text { situação diferente e possui uma história diferente, as crenças serão diferentes. }\end{array}$ \\
\hline Valores & $\begin{array}{l}\text { - são metas morais; } \\
\text { - são guias gerais para a ação; } \\
\text { - individualmente, estabelecem-se valores para organizar as ações; socialmente, compartilham-se valores } \\
\text { para criar previsibilidade e estabilidade social; } \\
\text { - é um compromisso de longo prazo por parte da organização ou do indivíduo, uma forte preferência e } \\
\text { um princípio organizador; }\end{array}$ \\
\hline Normas & $\begin{array}{l}\text { - expectativas que se têm uns dos outros em relação a atuação, regras, leis, jeito certo, etc.; } \\
\text { - podem ser procedimentos simples a serem seguidos ou expectativas informais, tradições, leis ou } \\
\text { princípios morais; } \\
\text { - cada um obedece às normas por motivos diferentes: compromisso moral; medo; expectativa de } \\
\text { recompensa; crença de que as normas são necessárias; } \\
\text { - simplesmente aceita-se a maior parte das normas sem refletir sobre se as alternativas poderiam ser } \\
\text { mais racionais ou justas; } \\
\text { - toda situação social é governada por normas: comer; vestir-se; andar; dormir; modo de adorar Deus; } \\
\text { nascimento; morte; sentimento de dor, etc. }\end{array}$ \\
\hline
\end{tabular}

\section{MODELOS DE ATENÇÃO EM SAÚDE E EXPLICATIVOS DO PROCESSO SAÚDE-DOENÇA}

Se for certo que em todas as sociedades complexas existem setores de cuidado, também é certo que existem modelos em disputa, cujas variações são determinantes fundamentais do espaço.

A construção da hegemonia dá-se pela legalidade e legitimidade, de forma que a primeira garante o reconhecimento por um conjunto de leis e de agentes que as fazem cumprir, e a segunda garante o reconhecimento no plano simbólico, ético e moral. Como as sociedades estão em movimento, também os diferentes modelos de saúde estão em processo, de forma que são identificadas mudanças na hegemonia e na homogeneidade dos modelos.

Da ciência política sabe-se que o instituinte das mudanças é a variação na correlação de forças dos blocos de poder em disputas. Cada novo momento de alteração de poder apresenta reflexos na política, na construção de modelos de operação/desenvolvimento e na forma de gerenciamento. Ao transpor essa matriz teórica para o campo da saúde brasileiro, reconhecem-se, ao longo das últimas décadas, blocos de poder público e privado, que criaram políticas, sustentaram socialmente a construção de modelos de organização dos serviços de saúde e exibem formas gerenciais específicas, de acordo com seu ideário 27,28 .

\begin{tabular}{|c|c|c|c|}
\hline $\begin{array}{c}\text { Modelos de Organização } \\
\text { Pública no Brasil }\end{array}$ & Gerenciamento & $\begin{array}{c}\text { Modelos de Organização } \\
\text { Privada }\end{array}$ & Gerenciamento \\
\hline Modelo de saúde pública & $\begin{array}{l}\text { campanhista e vertical } \\
\text { permanente }\end{array}$ & prática autônoma & descentralizado \\
\hline $\begin{array}{l}\text { Modelo de assistência } \\
\text { médica previdenciário }\end{array}$ & descentralizado centralizado & $\begin{array}{l}\text { prática autônoma } \\
\text { prática assalariada }\end{array}$ & descentralizado \\
\hline Medicina comunitária & descentralizado & prática assalariada & descentralizado \\
\hline $\begin{array}{l}\text { Reforma sanitária / } \\
\text { SUDS/ SUS }\end{array}$ & $\begin{array}{l}\text { municipalizado } \\
\text { hierarquizado } \\
\text { integral } \\
\text { controle social }\end{array}$ & $\begin{array}{c}\text { medicina de grupo } \\
\text { prática cooperativa } \\
\text { autogestão } \\
\text { planos de administração } \\
\text { seguro saúde }\end{array}$ & centralizado \\
\hline
\end{tabular}


O ideal é que já tivéssemos superado as tipologias sociopsicomédicas, psicossociomédicas ou médico-psicossociais, tendo alcançado a integralidade e a totalidade, mas há várias dificuldades para essa concretização.

Crendo que a melhor estrutura dos problemas é a que utiliza elementos de diferentes modelos explicativos do processo saúde-doença, propõe-se: se a orientação inicial é a social, porém, obviamente, sobre um problema de saúde biológico, então elementos históricos do espaço - história dos conceitos, das técnicas de intervenção individual e das formas de intervenção coletiva sobre o problema biomédico (das políticas, das instituições, dos modelos de organização das práticas e das formas de administração) - devem somar-se a elementos da inserção da pessoa na estrutura social - papel, poder, prestígio e perspectiva - e na cultura - crenças, valores e normas -, com suas construções psíquicas.

Dessa maneira, trabalhando com os modelos explicativos histórico, sociológico, biomédico clínico e epidemiológico, e psicológico, são produzidos problemas, como, por exemplo, o de "Juninho Alves".

\section{"Problema Juninho Alves"}

Sábado de manhã. A família Alves chega ao Pronto-Socorro Municipal e é prontamente encaminhada para o atendimento de enfermagem.

D. Bernadete (mãe): - Estamos trazendo o Juninho, que começou de repente com essa falta de ar e chiado no peito. Ele não consegue respirar direito! Nós até temos plano de saúde, mas chegamos na cidade há pouco tempo porque o pai dele veio transferido pelo banco, não conhecemos ninguém, não temos a lista dos conveniados aqui na cidade, por isso viemos aqui...

Enfermeira Elisa: - O Juninho já teve isso antes?

D. Bernadete: - Isso nunca! Ele tinha de vez em quando nariz escorrendo, espirrava demais. Ah, mais essa... Não bastasse a confusão toda que é mudar de cidade! Ele anda meio esquisito, era brincalhão, não parava quieto um minuto. Agora fica pelos cantos, chorando à toa, um problema pra ir pra escola! Não gosta da professora, não quer brincar, ainda não tem nenhum amiguinho... Nem sei o que fazer... A professora me chamou na escola preocupada com a dificuldade dele de estabelecer novas relações.

Enfermeira Elisa: - Vamos cuidar dele. Vou examinar o Juninho e acompanhar vocês aqui até ele melhorar. Agora vou levá-los aqui ao lado, a Dra. Márcia vai atendê-los, porque ele precisa ser consultado por ela para se tomar a conduta necessária.

Dra. Márcia: - Já soube pela enfermeira da história do Juninho: seis anos, primeiro episódio de dispnéia. Vamos examinar esse menino e prescrever logo uma medicação. Voltarei em seguida para avaliar a resposta à medicação.

Juninho teve alta da emergência após ter melhorado e recebeu orientação sobre a necessidade de acompanhamento ambulatorial.

Quem o viu brincando com a irmã - "Você está doente, vem aqui que eu vou cuidar de você" - pensa que ele até gostou do pronto-socorro naquele sábado de manhã.

Entre as mudanças mais significativas desse novo formato de um "velho" problema, está o trabalho com a noção de totalidade e integralidade. Para desenvolver a primeira noção, inserimos o sujeito do problema numa estrutura mais ampla - a família -, na qual, como em qualquer família, se desenvolvem outros problemas. É importante ressaltar que a dinâmica desse grupo é formada por cada um de seus membros, em seus diferentes aspectos, mas é uma totalidade diferente da simples soma de cada parte ${ }^{29}$. Para trabalhar com a integralidade, apresentamos sujeitos inseridos, muitas vezes, em espaços iguais, mas em territórios diferentes. Assim, a família de "Juninho", que tem uma condição social de renda média, habita diferentes territórios da saúde frente aos problemas que apresenta. Em outros termos, portanto, mesmo tendo acesso a serviço privado de saúde, a família foi levada a procurar o apoio do serviço público de saúde por uma situação de emergência e pela circunstância da mudança.

\section{Estrutura do problema "Juninho Alves"}

Problema explicativo - diferentes aspectos do processo são explicitados, deixando claros os mecanismos causais

1. Tempo - presente.

2. Espaço - território do município de Marília.

3. Organização das práticas 


\begin{tabular}{|c|c|}
\hline Prática & Procedimento \\
\hline Profissional & consulta de urgência no pronto-socorro e procedimento \\
\hline Popular & com a mudança recente, faltam referências dos agentes do setor popular de cuidado \\
\hline Informal & com a mudança recente, faltam referências da rede social \\
\hline
\end{tabular}

4. Modelo de atenção - atendimento de pronto-socorro no SUS

5. Pessoa

\begin{tabular}{|c|c|c|c|c|}
\hline Caract./sujeitos & Alves (35) & Bernadete (33) & Juninho (6) & Clara (4) \\
\hline \multicolumn{5}{|l|}{ Estrutura Social } \\
\hline Papel social & $\begin{array}{l}\text { pai / marido / } \\
\text { bancário }\end{array}$ & $\begin{array}{l}\text { mãe / mulher / } \\
\text { professora }\end{array}$ & 1 filho / estudante & 2 filho \\
\hline Identidade & trabalhador / bom pai & cooperativa / boa mãe & sensível & esperta \\
\hline $\begin{array}{l}\text { Poder } \\
\text { Capital econômico } \\
\text { Capital social } \\
\text { Capital técnico }\end{array}$ & $\begin{array}{l}10 \text { salários mínimos } \\
\text { negociador } \\
\text { contabilista }\end{array}$ & $\begin{array}{l}3 \text { salários mínimos } \\
\text { cria relações facilmente } \\
\text { técnica congelados }\end{array}$ & $\begin{array}{l}- \\
\text { honesto } \\
-\end{array}$ & - \\
\hline $\begin{array}{l}\text { Perspectiva/ } \\
\text { objetivos }\end{array}$ & $\begin{array}{l}\text { promoção gerência } \\
\text { regional em dois anos }\end{array}$ & $\begin{array}{l}\text { definir mais e manter o } \\
\text { corpo }\end{array}$ & $\begin{array}{l}\text { voltar para a outra } \\
\text { escola }\end{array}$ & brincar com o irmão \\
\hline \multicolumn{5}{|l|}{ Cultura } \\
\hline Crenças (moral) & pode ficar rico & pode manter-se jovem & $\begin{array}{l}\text { pode voltar ao } \\
\text { passado }\end{array}$ & $\begin{array}{l}\text { pode mandar em } \\
\text { todos }\end{array}$ \\
\hline $\begin{array}{l}\text { Valores (metas } \\
\text { morais) }\end{array}$ & honestidade / ética & estética & verdade & encantamento \\
\hline $\begin{array}{l}\text { Cumprimento das } \\
\text { normas }\end{array}$ & $\begin{array}{l}\text { expectativa de } \\
\text { recompensa }\end{array}$ & Medo & $\begin{array}{l}\text { expectativa de } \\
\text { recompensa }\end{array}$ & $\begin{array}{l}\text { expectativa de } \\
\text { recompensa }\end{array}$ \\
\hline
\end{tabular}

\begin{tabular}{l|l|l|l|l}
\hline Problema saúde & gastrite & higiomania & bronquite & otite de repetição \\
\hline
\end{tabular}

6. Modelo explicativo

\begin{tabular}{l|l}
\hline \multicolumn{1}{c|}{ Modelo explicativo } & \multicolumn{1}{c}{ Elementos } \\
\hline Social / histórico & Relação da nova estrutura social e da cultura da nova escola com a doença \\
\hline Biomédico clínico & morfofisiologia da bronquite \\
\hline Biomédico epidemiológico & números e custos da bronquite infantil (local e nacional) \\
\hline Psicológico & relação entre tristeza e doença \\
\hline
\end{tabular}




\section{ORGANIZAÇÃO DAS PRÁTICAS DE SAÚDE}

Em qualquer sociedade complexa, é possível identificar a (co)existência de diferentes formas de assistência à saúde ${ }^{30}$. Essa pluralidade pode ser compreendida pelo fato de que os sistemas médicos ${ }^{31}$ ou racionalidades médicas ${ }^{32}$ possuem dois aspectos inter-relacionados: um aspecto cultural, que inclui determinados conceitos básicos, teorias, práticas normativas e formas comuns de percepção; e um aspecto social, que inclui sua organização em determinados papéis específicos (como os de médico e de paciente) e princípios que regem as relações entre estes papéis em ambientes específicos (no hospital, no consultório médico, no centro de saúde, etc. $)^{30}$.

As formas de assistência são diferenciadas pela estrutura constituída pelos complexos cultural e social, e podem ser identificadas como informal, popular e profissional.

As práticas profissionais são desenvolvidas pelos profissionais da medicina oficial e constituem um grupo de "curandeiros" cuja atividade é assegurada por um conjunto de leis ${ }^{33,34}$. Eles gozam de status social mais alto, renda maior, além de direitos e obrigações mais claramente definidos do que os outros tipos de curandeiros. Têm o poder de interrogar e examinar seus pacientes, prescrever tratamentos e medicamentos poderosos e, algumas vezes, perigosos, e privar algumas pessoas de sua liberdade - confinando-as em hospitais - se estas forem diagnosticadas como psicóticas ou infecciosas. No hospital, eles podem controlar rigorosamente a dieta, comportamento, padrões de sono e medicação do paciente, além de introduzir uma variedade de exames - biópsias, radiografias ou secções de veias. Podem ainda rotular seus pacientes (em alguns casos, permanentemente) como doentes, incuráveis, simuladores, hipocondríacos ou plenamente recuperados - um rótulo que pode entrar em conflito com a perspectiva do paciente ${ }^{30}$.

Essas práticas podem ser identificadas em diferentes estruturas, ações e agentes, de acordo com o quadro a seguir.

\section{Práticas Profissionais}

\begin{tabular}{|c|c|c|}
\hline Instituições & Ações (procedimentos) & Agentes \\
\hline Posto de saúde & atenção primária & \multirow{8}{*}{$\begin{array}{l}\text { profissionais da área da saúde com } \\
\text { formação técnica e superior } \\
\text { profissionais administrativos com } \\
\text { formação técnica e superior }\end{array}$} \\
\hline Unidade de Saúde da Família & $\begin{array}{l}\text { atenção primária, secundária e visita } \\
\text { domiciliar }\end{array}$ & \\
\hline Centro de Saúde & atenção primária e secundária & \\
\hline $\begin{array}{l}\text { Policlínica (centros especializados de } \\
\text { referência) }\end{array}$ & atenção secundária e terciária & \\
\hline Pronto atendimento e pronto-socorro & urgência e emergência & \\
\hline $\begin{array}{l}\text { Hospital (diferentes níveis de } \\
\text { complexidade) }\end{array}$ & $\begin{array}{l}\text { atenção primária, secundária, terciária, } \\
\text { quartenária e internação hospitalar }\end{array}$ & \\
\hline Resgate de urgência & urgência e emergência & \\
\hline $\begin{array}{l}\text { Centros administrativos de Saúde } \\
\text { Coletiva (municipal, estadual e federal) }\end{array}$ & programas e campanhas específicas & \\
\hline
\end{tabular}

Entre as práticas profissionais, há um conjunto de instituições, ações e agentes que têm os atributos oficiais para o exercício da prática, mas desenvolvem outros sistemas ou racionalidades. Trata-se das chamadas práticas alternativas e complementares, em franco crescimento do número de usuários e praticantes e, por isso, com forte apelo para o aumento de investigações sobre sua eficácia, eficiência, padrão de formação, custo e possibilidade de inserção nos sistemas nacionais de saúde ${ }^{35}$.
O quadro das instituições, ações e agentes dessas práticas ainda não está muito bem definido, mas sabemos que, além de se desenvolver nos espaços oficiais, também se expande em outras instituições, dadas as suas características.

Um segundo conjunto de práticas de cuidado e cura disponível nas sociedades complexas é o das práticas populares. É necessário afirmar que elas são compreendidas como um conjunto de práticas e, portanto, não formam um sistema ou uma racionalidade. $\mathrm{A} \mathrm{OMS}^{35}$ as denomina como práticas da 
medicina tradicional, para diferenciá-las das práticas alternativas e complementares. São, em grande parte, realizadas por curandeiros populares que compartilham os mesmos valores culturais básicos e visões de mundo das comunidades em que vivem, incluindo crenças sobre a origem, significado e tratamento de doenças. Sua abordagem é, geralmente, holística, pois trata de todos os aspectos da vida do paciente, inclusive seus relacionamentos com outras pessoas, com o meio ambi- ente natural e com poderes sobrenaturais, além de seus sintomas emocionais e físicos.

O quadro de instituições, ações e agentes das práticas populares é bem menor que o da alternativa profissional, pelo fato de que elas não são a prática oficial e se mantêm como resistência cultural das populações periféricas das grandes cidades ou das comunidades com forte ascendência rural.

\section{Práticas Populares}

\begin{tabular}{|c|c|c|}
\hline Instituições & Ações (procedimentos) & Agentes \\
\hline Farmácias & \multirow{5}{*}{$\begin{array}{l}\text { preparados à base de partes vegetais, } \\
\text { animais e minerais (chás, xaropes, } \\
\text { garrafadas, alimentos, etc.) } \\
\text { rituais de cura } \\
\text { benzimento e reza (descarrego, passes, } \\
\text { cultos, etc.) }\end{array}$} & \multirow{5}{*}{$\begin{array}{l}\text { curadores com formação prática } \\
\text { mateiros } \\
\text { líderes religiosos (padres, pastores, } \\
\text { rezadores, benzedeiros, videntes, etc.) }\end{array}$} \\
\hline $\begin{array}{l}\text { Igrejas católicas } \\
\text { Igrejas pentecostais }\end{array}$ & & \\
\hline Centros espíritas kardecistas & & \\
\hline candomblé & & \\
\hline Residências particulares & & \\
\hline
\end{tabular}

A terceira alternativa de cuidado de saúde é um conjunto de ações não estruturado e não oficial. São as práticas informais, constituídas por uma série de relações de cura informais e não pagas, de duração variável, que ocorrem na própria rede social do paciente ${ }^{29}$, particularmente na família. Ela é a sede primeira da assistência à saúde em qualquer sociedade. Na família, os principais responsáveis pela assistência à saúde são as mulheres, geralmente as mães ou as avós, que diagnosticam as doenças mais comuns e as tratam com os recursos disponíveis ${ }^{30}$. Há estimativas de que cerca de $70 \%$ a $90 \%$ dos tratamentos de saúde ocorrem neste setor, tanto nas sociedades ocidentais quanto nas não ocidentais. As pessoas, quando "adoecem", obedecem normalmente a uma "hierarquia de recursos", que vai desde a automedicação até a consulta a outras pessoas ${ }^{31,35}$.

Os encontros terapêuticos acontecem sem regras determinadas de comportamento e ambiente, e têm duração vari- ável. Os papéis podem ser invertidos, e o paciente de hoje poderá ser o curandeiro amanhã. Determinados agentes, contudo, tendem a atuar como fontes de aconselhamento à saúde mais do que outros. São eles: aqueles com longa experiência numa doença específica ou num determinado tipo de tratamento; aqueles com larga experiência em acontecimentos da vida, como mulheres que criaram muitas crianças; os profissionais técnicos (enfermeiros, farmacêuticos, fisioterapeutas, recepcionistas de médicos, etc.), consultados informalmente a respeito de problemas de saúde; esposas ou maridos de médicos, que compartilham as experiências de seus cônjuges, às vezes até com algum treinamento na área; indivíduos tais como cabeleireiros, vendedores ou até gerentes de banco, que se relacionam com freqüência com o público e, algumas vezes, atuam como confidentes ou psicoterapeutas leigos; coordenadores de grupos de auto-ajuda; e membros de determinados cultos de cura ou igrejas ${ }^{30}$ 


\section{Práticas Informais}

\begin{tabular}{|c|c|c|}
\hline Instituições & Ações (procedimentos) & Agentes \\
\hline Igrejas & \multirow{4}{*}{$\begin{array}{l}\text { atividades de cura a } \\
\text { ssistência mútua } \\
\text { autotratamento } \\
\text { automedicação } \\
\text { consulta com mães/avós, que } \\
\text { diagnosticam e tratam } \\
\text { conselho ou tratamento recomendado } \\
\text { por parente, amigo, vizinho ou colega } \\
\text { de trabalho } \\
\text { consulta a outra pessoa leiga que tenha } \\
\text { experiência específica numa desordem } \\
\text { particular ou num tratamento de } \\
\text { determinado estado físico }\end{array}$} & \multirow{4}{*}{$\begin{array}{l}\text { líderes religiosos } \\
\text { líderes comunitários } \\
\text { parente } \\
\text { amigos } \\
\text { vizinho } \\
\text { colega de trabalho } \\
\text { pessoa que tenha sofrido da mesma } \\
\text { doença }\end{array}$} \\
\hline Grupos de auto-ajuda & & \\
\hline Residências & & \\
\hline Lugares públicos & & \\
\hline
\end{tabular}

\section{CONSIDERAÇÕES FINAIS}

Certamente, um dos fatos mais importante das duas últimas décadas no campo da saúde foram os debates em torno das mudanças nos currículos das escolas médicas. Várias propostas foram formuladas, e algumas escolas promoveram reformas com poucas mudanças, ao passo que outras assumiram mudanças profundas na forma e conteúdo de ensino.

A Faculdade de Medicina de Marília foi uma das escolas que mudou em profundidade e desde 1997 vem construindo o melhor formato para o desenvolvimento da Aprendizagem Baseada em Problemas. Como se pode prever, enfrenta problemas de várias ordens, pois se trata de uma mudança estrutural e cultural numa das instituições mais "reprodutoras" da ordem social.

Entre as dificuldades está o ensino da dimensão coletiva do processo saúde-doença por meio dos problemas. Não se trata de uma tarefa simples: por um lado, existe a forte presença da clínica individual do caso; por outro, a perspectiva coletiva, na sua dimensão macrossocial, não encontra relação direta e imediata com o problema individual.

Nosso objetivo foi apresentar uma proposta de inserção da dimensão coletiva, aquilo que os alunos chamam de "social", na construção dos problemas. Para isso, fundamentalmente, trabalhamos com as noções fundantes da Saúde Coletiva - tempo, espaço e pessoa - para alcançar a determinação multicausal da doença e as noções de totalidade e integralidade.

\section{REFERÊNCIAS}

1. Almeida M. J. Educação médica e saúde: possibilidades de mudanças. Londrina, Rio de Janeiro: UEL/ABEM; 1999.
2. Almeida M. J., Fuerwerker L. C. M, Llanos, M. V. A educação dos profissionais de saúde na América Latina: teoria e prática de um movimento de mudança. São Paulo/Londrina: ABEM/UEL; 1999.

3. Santos R C, Piccini R, Fachhini L A Org. Proposta:preparando a transformação da educação médica brasileira:projeto CINAEM III fase: relatório 1999-2000. Pelotas: UFPel; 2000.

4. Feurwerker L C, Almeida M.J. Integração ensino/serviço: a experiência da rede unida. In: Negri B.,FARIA R, VIANA, A. L. D, orgs. Recursos humanos em saúde: política, desenvolvimento e mercado de trabalho. Campinas: Unicamp/ NEPP; 2002. p 161-186.

5. Feurwerker L C. M Mudanças na educação médica: os casos de Londrina e de Marília. [Tese] São Paulo: USP / FSP; 2002.

6. Marsiglia R. M. G. Relação ensino/aprendizagem: dez anos de integração docente-assistencial (IDA) no Brasil. São Paulo: Hucitec; 1995.

7. Rede Unida. Contribuição para as novas diretrizes curriculares dos cursos de graduação da área da saúde. Olho Mágico 1998; 4 (16).

8. Rede Unida. A construção de modelos inovadores de ensino-aprendizagem: as lições aprendidas pela rede UNIDA. Divulgação em Saúde Debate 2000; 22.

9. Ceccim R. B , Feuerwerker L. C. M. Mudança na graduação das profissões de saúde sob o eixo da integralidade. Cad. Saúde Pública 2004; 20 (5):1400-1410.

10. Nunes E. D. Sobrea Sociologia da Saúde.SãoPaulo:Hucitec; 1999.

11. Schmidt H. G. Foundations of problem-based learning: some explanatory notes. Medical Education 1993; 27:422-432. 
12. Schmidt H. G. Educational aspects of Problem-Based Learning. English translation of: Onderwijskundige aspecten van probleemgestuurd onderwijs. In: Jochems W. M. G, eds. Aktiverend onderwijs. Delft: Delftse Univsersitaire Pers. [s.d.]

13. Komatsu R. S. Aprendizagem baseada em problemas: sensibilizando o olhar para o idoso. Londrina/Rio de Janeiro/ São Paulo: Rede UNIDA/ABEM/SBG/GSP; 2003.

14. Caprara A. A construção narrativa de problemas. In: Mamede S, Penaforte J., orgs. Aprendizagem baseada em problemas: anatomia de uma nova abordagem educacional. Fortaleza: Hucitec; 2001.

15. Ferrari. A. T. Epistemiologia e metodologia da sociologia. Campinas: Maranata; 1977.

16. Santos B de S. Introdução a uma Ciência Pós-Moderna. Rio de Janeiro: Graal;1989.

17. Santos B de S. Um discurso sobre as ciências. $7^{\circ}$ ed. Porto: Afrontamento; 1995.

18. Santos B de S. A crítica da razão indolente: contra o desperdício da experiência. São Paulo: Cortez; 2000.

19. DCS. Dicionário de Ciências Sociais. 2 ed. São Paulo: FGV / MEC; 1987.

20. Ribeiro E.C. de O. Planejamento educacional em grupos multidisciplinares: uma experiência de assessoria no desenvolvimento de unidades de ensino na Faculdade de Medicina de Marília/ SP. Marília: FAMEMA; Relatório Anual do Projeto UNI,Marília; 2000.

21. Sartre J. P. Crítica de la razón dialéctica. Buenos Aires: Losada; 1970.

22. Venturelli J. Educación médica. Nuevos enfoques, metas y métodos.Washington :OPAS/OMS;1997. [Serie PALTEX Salud y Sociedad; $\mathrm{n}$ 5, 2000]

23. Dossey L. Espaço, tempo e medicina. São Paulo: Cultrix; 1999.

24. Santos M; A natureza do espaço. São Paulo: Hucitec; 1996.

25. Bourdieu P. A economia das trocas simbólicas. São Paulo: Perspectiva; 1994.
26. Achterberg J. A imaginação na cura: xamanismo e medicina moderna. São Paulo: Summus; 1996.

27. Cohn A., Elias P. E. Saúde no Brasil: políticas e organização de serviços. São Paulo: Cortez/ Cedec; 1996.

28. Silva Junior AG. Modelos tecnoassistenciais em saúde: o debate no campo da saúde coletiva. São Paulo:Hucitec;1998.

29. Sluzki C. E. A rede social na prática sistêmica. São Paulo: Casa do Psicólogo; 1997.

30. Helman C. Cultura, saúde e doença. Porto Alegre: Artes Médicas; 1994.

31. Workshop on alternative medicine. Alternative Medicine: expanding medical horizons. A report to the National Institutes of Health on Alternative Medical Systems and Practices in the United States. Chantilly, Virginia: The Office of Alternative Medicine/National Institutes of Health; 1992.

32. Luz M.T. Racionalidades Médicas e Terapêuticas Alternativas. Rio de Janeiro: UERJ/IMS; 1993

33. Machado M. H. Os médicos no Brasil: um retrato da realidade. Rio de Janeiro: Fiocruz;1997.

34. Machado M. H. Profissões de saúde: uma abordagem sociológica. Rio de Janeiro: Fiocruz;1995.

35. Organización Mundial de la Salud. Estrategia de la OMS sobre medicina tradicional 2002-2005. Ginebra:OMS; 2002.

\section{Conflito de Interesse}

Declarou não haver.

\section{Endereço para correspondência}

Nelson Felice de Barros

Rua Abílio Vilela Junqueira,681/2

13085-420 Campinas - São Paulo-SP

E-mail: nelfel@uol.com.br

Lídia C. de Almeida Lourenço

Rua Antônio Augusto Neto,195

17501-280 Campinas-SP

E-mail: lcal@terra.com.br 